\title{
LA IDENTIDAD DE «DES-EXILIO»: EL CASO DE MARÍA ZAMBRANO ${ }^{1}$
}

\begin{abstract}
Wachowska Judyta, La identidad de kdes-exilios: el caso de Maria Zambrano [The identity of «dis-exile»: the case of Maria Zambrano]. Studia Romanica Posnaniensia, Adam Mickiewicz University Press, Poznań, vol. XXXI: 2004, pp. 111-120. ISBN 83-232-1353-4, ISSN 0137-2475.

This article is a voice in understaning the problem of Spanish «dis-exile» from a perspective shown by María Zambrano. In her various writings one can follow a strict line of her philosophical thinking dedicated to the individual and historical consciouscness that an cxiled person can recover when he/she starts his/her journey to an unknown future: his/her soul is crossed by signs of centuries. That is why an exile, and dis-exile as its consequence, can become an apparent contra-diction: the fact of being deprived of a common and obvious reality lets reach one's origins of identity. María Zambrano herself was exilied for forty five years between 1939 and 1984 and this experience became an essential dimension of her life.
\end{abstract}

Tal vez busques un sitio en la tripulación de Odiseo por mucho tiempo

- compartirás largos días con ella-

- escribirás ahorrando las palabras -

aunque puedan ser raspadas en el mastil

un largo caminar - como la línea del hexámetro

que demarca la silueta del buque de madera

sólo la tripulación es siempre la misma:

ya que estas son las reglas de la travesía al igual que sus leyes

no se puede llamar a todos los que quieran

- ni más - ni menos

pero se puede tal vez

durante la ventisca - y con amigos en torno tuyo-

hablar largamente de lo de la poesia

sin conorer la variedad de sus significados

ni menos todavía la providencia - el destino

Wasyl Machno

${ }^{1}$ Este texto fue presentado en forma de comunicación en el simposio internacional organizado en Oxford, 7th Forum for Iberian Studies, dedicado al tema de: «Voicing Identities: Narrative of Identity in Contemporary Iberian Cultures (1975-2000)" y celebrado el 31 de Mayo y 1 de Junio de 2002. Algunos aspectos de aquella presentación han sido reelaborados para los fines de la presente publicación. 
György Lukács explicaba en su Teoría de la novela que los tiempos felices fueron aquéllos en los que el cielo estrellado funcionaba como el mapa de los caminos abiertos, iluminados, que acogían al peregrino. En tal situación todo parecía ser nuevo, pero era una novedad familiar y conocida, todo parecía ser aventurero, no obstante se trataba de una aventura apropiada, pertinente. El ancho mundo era como el hogar, como la casa, porque el fuego encendido en el alma del peregrino tenía el mismo origen que el fuego de las estrellas (Lukács, 1968: 21). No obstante, en los días en que Lukács escribía este gran ensayo germinaba ya la primera guerra mundial y el autor de esas palabras estaba consciente de una fuerte alienación y soledad del ser humano de aquella época, de una época que erguía los fundamentos de un mundo incoherente, en el que el ser humano con su «espacio espiritual» se veía y sentía por lo menos abandonado. De ahí, que finalmente constatará que este cielo acogedor, estrellado [kantiano] relucía ya tan sólo en la noche oscura del conocimiento puro y dejaba ya de iluminar el camino a cualquier viajero. El hombre significaba para Lukács lo mismo que el ser solitario (Lukács, 1968: 29).

Efectivamente, una de las sombras proyectadas por el siglo $\mathrm{XX}$, «el siglo del desencanto ${ }^{2}$, es indudablemente la del exilio. Guerras ideológicas, totalitarismos, batallas étnicas y religiosas han forzado a millones de personas, ciudadanos de distintos países, a andar por otras tierras, conocer otros cielos, vivir realidades distantes y ajenas... El profesor Leszek Kołakowski (exiliado en Inglaterra, residente en Oxford) advierte en un ensayo que vivimos en una época de fugitivos, errantes, vagabundos, nómadas que al recorrer los continentes calientan sus almas con imágenes de casa, sea espiritual o ética, celeste o geográfica, real o delirante (Kołakowski, 1985). De ahí que podríamos decir que los desterrados, al igual que los eternos peregrinos, aprenden a llevar consigo su hogar, llevar su memoria y su belleza, saber cuidarlo y recrearlo en cada lugar de refugio, llevar «la presencia física del país perdido", como dijo Maria Zambrano. Es por eso que Kołakowski explica más adelante en del mismo texto que el quedarse sin casa en absoluto es insoportable, al igual que no es posible un cosmopolitismo absoluto, porque tal situación significaría una ruptura con la existencia humana.

El intelectual exiliado es un personaje muy bien conocido en el siglo XX y tiene una larga trayectoria espiritual. Desde Ovidio, Dante y Séneca, hasta los que han tenido que pasar por el horror de los grandes movimientos migratorios del siglo $\mathrm{XX}$, dentro de los cuales los españoles de la guerra civil del 36 se inscriben en una forma inmediata. $Y$ aunque, desgraciadamente, podemos decir que fue un fenómeno masivo, la dictadura franquista decretó su inexistencia, a pesar de una minoría (comparado con las cifras que hoy en día se conocen) de personas que creía

${ }^{2}$ Aludimos aquí al libro de la escritora mexicana Angleina Muñiz Huberman, hija de refugiados españoles de 1936, que es un intento de resumir la experiencia del siglo veinte partiendo de las experiencias de los exilios. 
indeseables. Para ocultarlo se creó toda una máquina de censura en que la censura de prensa era sólo uno de toda una variedad de mecanismos. Junto a ella, observó José Luis Abellán, habría que colocar el control aduanero de las publicaciones, la inspección de librerías, el expurgo de bilbiotecas, los registros domiciliarios, los procesos a los detentadores de publicaciones consideradas clandestinas (Abellán, 2001: 112), etc.

Si aparentemente los estudios acerca del tema del exilio español de la guerra civil de 1936 están últimamente bastante bien cuidados ${ }^{3}$, apenas se encuentran trabajos que hablen de la realidad del des-exilio. De un lado tal situación parece ser inteligible ya que primero hay que recuperar cerca de cuarenta años (en unos casos menos, en otros más) de la creación intelectual, artística y simplemente humana, dispersada tanto por Europa como, sobre todo, por los continentes americanos. Tal investigación requiere un enfoque desde distintas perspectivas, tan diversas -digamos- como polifacético y multidimensional puede resultar un exilio: desde los aspectos relacionados con la política, la historia, el derecho, hasta los que tienen que ver con la psicología, sin olvidar los campos que forman el núcleo de nuestro interés, es decir los de los estudios literarios, filosóficos y de ciencias de la cultura.

La característica que intenta sumar la experiencia histórica de la emigración de la guerra civil demarca dos grandes corrientes que dieron origen a la diáspora: la primera fue formada esencialmente, aunque no en todo, por pequeña burguesía e intelectuales y condujo hacia las tierras americanas (sobre todo a México); la segunda tuvo una base más popular y sindical y se acomodó en varios países europeos, esencialmente en Francia (Andújar, 1976: 15). Dentro del número muy general que suma más de medio millón de personas que decidieron huir a través de las fronteras para respirar el aire de libertad que se les negaba en su pais, sólo el diez por ciento, o sea, cerca de 50.000, consiguieron llegar a la seguridad de las tierras americanas. La inmensa mayoría que se buscó la suerte en Europa se encontró con un destino muchas veces más cruel y desafortunado. Recordemos que si oficialmente la guerra civil terminó el día 1 de abril de 1939, toda Europa vivió ya el temeroso estado de preguerra, que justo en cinco meses en adelante se convertiría en un apocalipsis de alcance mundial cuyo terreno de desafío más doloroso sería el Viejo Continente. Total, que los exiliados que no decidieron regresar rápidamente a España (a una España en que les esperaba la dictadura con sus represiones), se enfrentaron con la barbarie de la nueva guerra, en algunas de cuyas dimensiones cayeron víctimas de la violencia o la muerte organizada, del hambre, de la enfermedad, del cúmulo de penalidades en los campos de refugiados del sur de Francia (Saint Cyprien, Argelès, Barcarès, Gurs...), de castigo y trabajos forzados (Le Vernet [Francia]; Djelfa, Berrouaghia [Argelia], Buchenwald, Orianemburg

${ }^{3}$ La muerte de Franco en 1975 provoca la posibilidad de publicaciones acerca de cuestiones prohibidas por la censura dictatorial; sin embargo en este caso particular es el año 1989, el cincuentenario del fin de la guerra, cuando se da un verdadero auge de publicaciones, trabajos, congresos y seminarios que en distintas areas realizan la labor de investigación. 
[Alemania], y de exterminio (Mauthausen [Austria]; Dachau [Alemania]) (NaharroCalderón, 1991: 12).

Sin embargo, los caminos de la «España peregrina» lograron entretejer no tan sólo los espacios geográficos, sino también vastos territorios de la creación humana, respecto a los cuales precisamente Manuel Andújar inventó la expresión de «mestizaje cultural» relacionada, sobre todo, con los más afortunados que se refugiaron en los países del habla hispana. Llamados de distintas maneras, «transterrados» por José Gaos, quien aludía a un nuevo descubrimiento de América en términos vivencial-intelectuales, o «conterrados» por Juan Ramón Jiménez, quien inventó este término para expresar sobre todo el entusiasmo linguístico de poder encontrarse en un recinto de idioma español. Los escritores, pensadores y artistas, profesores y científicos aportaron a las culturas de los países americanos un enorme bagaje intelectual en los distintos campos de su interés profesional.

María Zambrano abandonó la tierra española a finales de enero de 1939 y regresó como una de los últimos desterrados, en noviembre de 1984, siendo ya una señora mayor, a los ochenta años de edad. Durante ese período de casi medio siglo los pasos de su exilio la llevaron a varios sitios. Al principio a la tierra latina: sobre todo a México, Cuba y Puerto Rico, donde residió con dos años de interrupción ${ }^{4}$ hasta 1953. Y después estuvo en Europa, instalándose en Italia, Francia y Suiza. Trazó muchos lugares, al igual que sus compatriotas de destierro, experiencia que años más tarde, cuando ya regresó a España, describiría con esas palabras:

El exilio, por tanto, ha sido ante todo, y más que nada, diáspora: los amigos perdidos, las ocasiones frustradas, el intento siempre abjerto de una nueva patria que las abrace a todas (...). La derrota que dio origen al exilio mío y de millones de gentes inclusive durante muchos años fue, ya lo he dicho, diáspora; no se sabía dónde estaba nadic, a veces entre la niebla se los encontraba, a veces aparecían con una forma distinta: eran los nuevos amigos (...). De ahí que mi ferviente voto, ofrenda, es que no se repita, que no se repita más la guerra civil en parte alguna del mundo, que los hombres encuentren una patria común que, sin dejar de ser patria y singularmente suya, sea al par de todos los hombres. (1988: 86).

Los exiliados son como islas humanas, a las cuales el tiempo, la historia, y su propio afán los traslada por los senderos del mapa mundis. E igual como las islas están suspendidas entre el mar y el cielo, sin ocupar un lugar aparentemente fijo en el mundo, con sólo un poco de tierra, «suficiente para sostener el paso del hombre» (Zambrano, 1989b: 241). Ser exiliado es «no ser nadie, ni un mendigo: no ser nada. Ser tan sólo lo que no puede dejarse ni perderse» (1990: 36). Es por eso que nuestra autora hable de la necesidad de la conciencia de la formación histórica, tanto la individual, como la más global. Lo definió en otro escrito dedicado al tema en cuestión, Amo mi exilio, explicando que los exiliados al emprender el viaje en un futuro desconocido tenían el alma cruzada por huellas de siglos, «son más grandes

${ }^{4}$ De 1946 a 1948 estuvo en París con su hermana Araceli, ciudad a la cual llegó para el entierro de su madre. 
las raíces que las ramas que ven la luz» (1995: 14). Esas raíces daban la posibilidad, a veces la certidumbre, de poder cargar su peso en la tierra, la incierta tierra de un vagabundo. La integridad personal, el ir recuperando los fragmentos de la patria ausente en todos los significados reales y figurativos, la formación de la conciencia de la identidad es todo un proceso que lo describió de la siguiente manera:

La Patria es como el Mar que recoge cl río de la muchedumbre. Esa muchedumbre en la que uno va sin marcharse, sin perderse, el Pueblo, andando al mismo paso con los vivos y con Jos mucrtos.

$\mathrm{Y}$ al salirse de ese mar, de esc río, sólo entre cielo y tierra, hay que recogerse a sí mismo y cargar con el propio peso; hay que juntar toda la vida pasada que se vuelve presente y sostenerla en vilo para que no se arrastre. No hay que arrastrar el pasado, ni el ahora; el día que acaba de pasar hay que llevarlo hacia arriba, juntarlo con todos los demás, sostencrlo. Hay que subir siempre. Eso es el destierro, una cuesta, aunque sea en el desierto. Esa cuesta que sube siempre y, por ancho que sea el cspacio a la vista, es siempre estrecha. $Y$ hay que mirar, claro, a todas partes, atender a todo como un centinela en el último confín de la tierra conocida. Pero hay que tener corazón en lo alto, hay que izarlo para que no se hunda, para que no se nos vaya. Y para no ir uno, uno mismo haciéndose pedazos (1986: 259).

La integridad personal, ese «no estar hecho pedazos», fue una tarea a la que la pensadora andaluza se mantuvo fiel, descubriéndola no sólo en su circunstancia individual e histórica, sino también en su labor intelectual: la del pensamiento. El carácter específico de su obra, cuyo hallazgo llamado la "razón poética" se sitúa al borde de dos grandes conocimientos humanos, experimentando tanto los espacios filosóficos, como los universos literarios, ambos continuamente interferentes en toda su escritura. Fue nómada también en este sentido, peregrinando entre estos dos saberes, dos modos distintos de percibir el mundo, dos maneras diferentes de la expresión humana. $O$, tal vez, dicho de otra manera, su forma de pensar y de escribir supo abolir la frontera que los separaba, abriendo ante ellos un nuevo universo libre de limitaciones y prejuicios, enfocado en un diálogo que conducía al encuentro. Un mundo múltiple, diverso, multicolor es, como creemos, más inquietante e inspirador, es un mundo en que se aceptan (con piedad y tan sólo con tolerancia $^{5}$ - como solía decir) la heterogeneidad de los pensamientos, de las creencias, de las etnias...

La labor intelectual de María Zambrano en el exilio fue muy activa. Durante aquellos años publicó cerca de veinte libros ${ }^{6}$ en varias editoriales latinoamericanas y también españolas (aunque las últimas fueron escasas), y además la mayoría de sus más de trescientos artículos. Colaboró con numerosas revistas latinoamericanas y europeas, ejerció la enseñanza en diversos centros académicos de México, Cuba y

\footnotetext{
${ }^{5}$ Véase su texto: Para una historia de la piedad, Málaga, Torre de las Palomas, 1989.

${ }^{6}$ Para consultar la bibliografía y biografía de María Zambrano, consúltese su mejor exposición hecha por Jesús Moreno Sanz [en] M. Zambrano, La razón en la sombra. Antología del Pensamiento de María Zambrano, edición a cargo de Jesús Moreno Sanz, Madrid, Ediciones Siruela, 1993, pp. 607653.
} 
Puerto Rico. Mientras seguía viviendo en el destierro, su nombre empezaba a resonar despacio y sutilmente en España. No obstante, en realidad su obra permaneció casi totalmente desconocida hasta alrededor del año 1980, cuando a propuesta de la colonia asturiana de Ginebra (ciudad en que vivía en aquel tiempo) fue nombrada hija adoptiva del Principado de Asturias, hecho que le otorgó el primer reconocimiento oficial en España después de 40 años de un aparente silencio $y$, en consecuencia, dio origen a casi una avalancha de premios y actos honoríficos: Premio Príncipe de Asturias de Comunicación y Humanidades en 1981 (fue la primera edición del mismo), hija predilecta de Vélez-Málaga, doctorado honoris causa de la Universidad de Málaga en 1982, entrevistas, números monográficos de revistas culturales, conferencias sobre su pensamiento. En aquella temporada favorable se creó el ambiente para su retorno y acogida, al mismo tiempo que la pensadora sabía ya que volvía para morirse, pero también tenía la esperanza de que se la escuchara y de que quizás pudiera dar alguna clase de filosofía...

Cuando en noviembre de 1984 pisó de nuevo el suelo español, bajando del avión en Barajas, dijo a los que estaban esperándola allí:

Si yo no vuelvo, no puedo volver porque yo no me he ido nunca; yo he llevado a España conmigo, detrás de mí, en el secreto y al par, luminoso o dramático o visible simplemente del corazón. Nunca se ha ido de mi corazón ni de mí, España. Yo diría, inclusive, que he sido exiliada para ser española de un modo más total (1988: 85).

Del verdadero significado de estas frases nos enteramos a través de un ensayo suyo llamado «El exiliado», que forma parte del libro Los Bienaventurados. Ahí la autora explica que el exilio es sobre todo una revelación que se le da al ser humano cuando, abandonado por su tierra en el sentido histórico, se siente sostenido «en el filo entre vida y muerte» y empieza a conocer una verdad íntima: se descubre en sus raíces. En resumidas palabras, el exiliado al darse cuenta de que la historia de su tierra le abandona, echándole al margen, deshaciéndose de él, anda para siempre desterrado en el mundo y se convierte en un peregrino que, a la vez descubre su identidad. Es más, el hecho de no estar dentro de una realidad que le es obvia y común, «junto con otros vivos y muertos», le ofrece al desterrado un regalo aparentemente contradictorio: llegar hasta el origen de la identidad. Sin embargo tiene que ir formando esta identidad, esculpiéndola por los caminos de su peregrinaje. Por eso el exilio es una experiencia que logra, según María Zambrano, unos fines totalmente opuestos: «el exilio es el lugar privilegiado para que la Patria se descubra” (1990: 29-44). La patria -explicó- que es solamente una categoría histórica, no atribuida por la autora ni a la tierra ni a la casa (ni, por supuesto, a otras dimensiones políticas), ya que forman todas unos recintos diferentes en que el lugar de origen e inicio se configura de distintos modos. De ahí entonces que España le acompañara siempre formando parte de su corazón, de su identidad, de su circunstancia en términos orteguianos. Es que la historia pertenece, según la división hecha por Dilthey, a las ciencias del espíritu que versan sobre el objeto de 
la creación humana. Por eso el conocimiento histórico significa para Zambrano (1964: 12) una comprensión gracias a la cual el hombre revive el pasado para sacar de él su esencia humana, conocerse a sí mismo y revelarse a sí mismo. Se puede afirmar, igualmente, que esa especie de revisión de la historia, de su profunda meditación, le sirvió a toda la «España peregrina» viendo en ella el reencuentro con una tradición a la que hubo que ir completando. Fueron lanzados de España para ser su conciencia, «memoria que rescata», dijo Zambrano, para que dispersados por el mundo «hayamos de ir respondiendo de ella, por ella; y fuera de su realidad seamos simplemente españoles; españoles sin España; ánimas de purgatorio» (1993: 389). En este sentido el exilio cobra una dimensión esencial para su vida, cuestión que confesó en el artículo ya mencionado Amo mi exilio, y añadió enseguida:

(...) pero al decirlo me quemo los labios, porque yo quería que no volviese a haber exiliados, sino que todos fueran seres humanos y la par cósmicos, que no se conociera el exilio. Es una contradicción, qué le voy a hacer; amo mi exilio, será porque no lo busqué, porque no fui persiguiéndolo. No, lo acepté; y cuando se acepta algo de corazón, porque sí, cuesta mucho trabajo renunciar a ello. Yo he renunciado a mi exilio y estoy feliz, y estoy contenta, pero eso no me hace olvidarlo, sería como negar una parte de nuestra historia y de mi historia. Los cuarenta años de exilio no me los puede devolver nadie, lo cual hace más hermosa la ausencia de rencor. Mi exilio está plenamente aceptado (...) (1995: 14).

Los pocos años que le fueron of recidos de nuevo en tierra española los pasó en Madrid, rodeada de amigos que venían a su casa, igual que en los viejos tiempos de antes del exilio cuando organizaba tertulias que frecuentaban escritores, poetas, artistas, "gente inquieta», amigos en fin. Igualmente no cesaba en su labor intelectual publicando nuevos libros sustanciales de un pensamiento cada vez más poético, más simbólico. Al mismo tiempo escribió múltiples artículos nuevos que aparecían con mucha regularidad en el suplemento cultural del Diario 16. En el año 1987 se constituyó en su pueblo natal Vélez-Málaga la fundación que lleva su nombre. Finalmente la coronación de galardones tuvo lugar al año siguiente con la concesión del Premio Cervantes, a cuya recepción no pudo acudir por graves problemas de salud. No obstante, los reyes y el entonces ministro de cultura Jorge Semprún, la visitaron en su domicilio. Ella, de todos modos, preparó para aquella ocasión un bello discurso sobre la humildad ante el destino, sobre el que la victoria a veces se encuentra en el fracaso porque hay acontecimientos que adelantan la historia, sobre el amor y la integridad en Don Quijote, sobre su exilio y «su» España, del cual nos permitos citar un fragmento:

Por amor a recuerdos y a vuestra generosa compañia, seguidme hasta una hermosa ciudad de México, Morelia, cuyo camino no busqué, sino que él mismo me llcvó a ella, igual que a tantos otros españoles recién llegados al desticro. Allí me encontré yo, precisamente a la misma hora que Madrid - mi Madrid - caía bajo los gritos bárbaros de la victoria. Fui sustraída entonces a la violencia al hallarme en otro recinto de nuestra lengua, cl Colegio de San Nicolás de Hidalgo, rodeada de jóvenes y pacientes alumnos. Y, ajena desde siempre a 
los discursos, ¿sobre qué pude hablarles aquel día a mis alumnos de Morelia? Sin duda alguna, acerca del nacimiento de la idea de libertad en Grecia. Era una forma natural de acordarme de España y del ya melancólico, resignado y esperanzado fracaso. Era la forma de situarse en aquella hermandad de una cultura que anunciaba la España del fracaso: la más noble tal vez, la más íntegra. La que forzosamente tuvo que fracasar, porque había ido más allă de su época (1989a: 53).

Al recibir el Premio Cervantes María Zambrano tenía 85 años y era ya una persona muy débil físicamente. A partir del año 1990 su estado de salud empeoró todavía más. Murió en los primeros días de febrero de 1991 y su cuerpo fue trasladado a Vélez-Málaga donde yace en el cementerio local. En su tumba están inscritas las palabras del Cantar de los Cantares: «Surge amica mea et veni».

Su desexilio, tal como dijo, no llevaba rencor. No fue un desexilio frustrado o fracasado. Claro que desde el punto de vista de la vanidad humana contribuyeron a ello varios homenajes que se rendidos a su persona. Sin embargo, María Zambrano no lo esperaba y no era exactamente esto lo que le daba la seguridad de su suerte. Al contrario, lo que prevalecía en su figura no fue el sacrificio, sino la ofrenda. Refiriéndose a su llegada a España, tan retrasada, cuando no veía el fin de su exilio, confesó en uno de sus artículos o, más bien dicho notas -pensamientos dispersadosque vuelcan acerca del hilo del «saber de la experiencia», que cada vez que pensaba en regresar le parecía que no era el momento adecuado y siempre lo posponía. El porqué de esas decisiones diferidas lo explica, como siempre de una manera simbólica, a través de una imagen que guardó en la memoria del cruce de la frontera de Francia. Era el día 28 de enero de 1939, uno de los últimos días en que centenares de personas decidieron abandonar el país dirigiéndose a la frontera francesa. Entre la inmensa muchedumbre en que se encontraba en aquel momento, le precedía un señor que llevaba a su espalda un cordero. Y entonces la imagen de aquella realidad se convirtió al pasar de los años en «la realidad de la imagen», es decir se había prometido volver de la misma manera: como la última de todos. Y cuando definitivamente finalizó su retorno se dio cuenta de que se había asimilado con aquel cordero, símbolo de alguien que acepta estar destinado a la muerte y gracias a las circunstacias aprende a trascenderla (1995: 15-17). Pero hay algo más referido a aquel pobre animal: vino aguardada por la gente. En otra ocasión dijo:

Pero, es que la distancia impone temor, porque la distancia se absolutiza, es el amor que se vuelve temor. (...) nadie me ha preguntado (...) acerca de lo que sentía cuando era inminente el exilio, la vuelta del exilio, el dejar de ser exiliada, ¿qué sentía? ¿un inmenso dolor, un inmenso remordimiento, una especie de... de sentirme culpable? en absoluto; no por volver, sino por haberme ido. ¿Por qué no me quedé Señor, por qué no me quedé? Y aquí corrí la suerte de los que se quedaron por amor (1988: 86).

El desexilio representa indudablemente la otra cara del exilio. Y su experiencia puede resultar igual de dolorosa como la de exilio, aunque sus raíces son de otro género. Mientras que el exilio es impuesto por situaciones ajenas a la voluntad de 
quien lo sufre, el desexilio forma parte de su responsabilidad. Sin embargo el exilio es, un término recíproco: el que abandona un sitio marchándose, deja un hueco y aunque corra mucha agua por ese lugar vacío no conseguirá taparlo. Por eso al exiliado, según y conforme las circunstancias históricas, se le guarda un sitio al que pueda volver o, por lo menos, se le sugiere que haya esta posibilidad. Pero muchos de los desexiliados son incapaces de adaptarse al viejo país que ofrece una nueva realidad, una realidad que desconocen y en la que les resulta extremadamente difícil reconocerse. El mismo tiempo que cambiaba a los exiliados cambiaba también la tierra que les hizo exiliar. $Y$ aunque se diga en muchas ocasiones que el exilio significa sobre todo una nostalgia del pasado, es al revés: encarna una nostalgia del futuro. El exiliado, el que piensa en desexiliarse, se imagina y hace unos planes meticulosos, sueña con la realidad de su retorno. Tal como lo expresó María Teresa León:

Un día se asombrarán de que lleguemos, de que regresemos con nuestras ideas altas como palmas para el domingo de los ramos alegres. Nosotros, los del paraíso perdido. ¿No comprendéis? Nosotros somos aquellos que miraron sus pensamientos uno por uno durante treinta años. Durante treinta años suspiramos por nuestro paraíso perdido, un paraíso nuestro, único, especial. (...) Nosotros somos los desterrados de España, los que buscamos la sombra, la silueta, cl ruido de los pasos del silencio, las voces perdidas. (...) Llegaremos. Regresaremos con la ley, os enseñaremos las palabras enterradas bajo los edificios demasiado grandes de la ciudades que ya no son nuestras (1970: 217).

En el año 1961, en el ensayo titulado Carta sobre el exilio, María Zambrano expresa el recelo de que se trate el exilio desde España como una realidad ignorada, olvidada o desconocida aún: "Ahora ya ni siquiera estamos en el exilio; estamos, debemos de estar "por ahî", no se sabe en qué lugar». Ese texto, publicado en París, fue una voz muy decidida, que por eso parecía más un grito, en defensa de los exiliados, de la necesidad de tomar la palabra desde fuera de España, de que la suerte y el destino de España no estuvieran determinados sólo por los que están en su tierra, viviendo su historia como un sueño, una pesadilla, un fatum no superado:

La prenda que el exiliado conserva entre sus manos, mientras mira al cielo sin interrogación y sin llanto, debe ser esa. Désele voz y palabra. No pide otra cosa sino que le dejen dar, dar lo que nunca perdió y lo que ha ido ganando: la libertad que se llevo consigo y la verdad que ha ido ganando en esta especie de vida póstuma que se le ha dejado (1993: 390).

Y para terminar quiero aludir al último texto.que María Zambrano publicó en su vida y que apareció a finales de noviembre de 1990, «su último acto escrito de esperanza y lucidez», como dijo Jesús Moreno Sanz, en que habló sobre la conciencia de la paz, aterrorizada esta vez no exactamente por la circunstancia española, sino ante los sucesos del Golfo Pérsico. No obstante, lo escrito, como siempre en su pensamiento, adquiere unas dimensiones universales siendo una indicación ética, obviamente también por la libertad y la verdad ganadas en el exilio. La vida establecida en la paz obliga a una postura moral, enseña la autora. 
Mientras el estado de paz esté determinado por el temor que provoca tan sólo la ausencia de guerra y no tenga sus orígenes en la plena conciencia moral que signifiqua «un modo de vivir, un modo de habitar en el planeta, un modo de ser hombre» crearemos un peligro implacable. Iremos fundando estados de terror que podrán repetirse en cualquier situación ocasional y nunca traspasaremos el umbral:

Y así, estado de paz verdadera no habrá hasta que surja una moral vigente y efectiva a la paz. encaminada, hasta que aquellas energías absorbidas por las guerras se encaucen, hasta que el heroísmo encuentre vías nuevas, el heroísmo de los que cifran en la guerra el cumplimiento de su vida, hasta que la violencia no sea cancelada de costumbres, hasta que la paz no sea una vocación, una pasion, una fe que inspire e ilumine (1995: 46).

\section{BIBLIOGRAFIA}

A bellán, J. L. (200I), El exilio como constante y como categoría. Madrid: Biblioteca Nueva. Colección Ensayos.

Andújar, M., Risco A. (1976), Crónica de la emigración en las revistas, en José Luis Abellán (ed.). El exilio español de 1939. Madrid: Taurus, vol. III.

Kolakowski, L. (11.10.1985), On Exile, en Times Literary Supplement. Aqui me sirvo de la traducción hecha al polaco por Marcin Borowicz. O wygnaństwie. Editado por una cditorial clandestina polaca y sin datos bibliográficos.

León, M. T. (1970), Memoria de melancolía. Buenos Aires: Losada.

Lukács, G. (1968), Teoria powieści. Traducción de Jan Goślicki. Warszawa: Państwowy Instytut Wydawniczy. Biblioteka Krytyki Wspólczesnej.

Machno, W. (2003), Wẹdrowcy. Traducción al polaco de Andrzej Nowak. Poznań: Bonami, 7. [la trad. del polaco al castellano es de la autora].

Naharro-Calderón, J.M. (Coord.) (1991), El exilio de las Españas de 1939 en las Américas: ¿Adónde fue la canción? Barcelona: Anthropos. Col. Memoria Rota, Exilios y Heterodoxias, Seric Estudios.

Zambrano, M. (1964), El hombre ante su historia, en Educación, 12. Pucrto Rico: Publicación del Departamento de Instrucción Pública, 11-17.

- (1986), La tumba de Antígona, en Senderos. Barcelona: Editorial Anthropos. Col. Memoria Rota, Exilios y Heterodoxias.

-(1988), El exilio, alba interrumpida, en Turia. Revista cultural, 9. Teruel.

- (1989a), Discurso de la entrega del Premio Cervantes, en María Zambrano. Premio de Literatura en Lengua Castellana «Miguel Cervantes» 1988. Barcelona: Anthropos. Ministerio de Cultura, Dirección General del Libro y Bibliotecas, 53-62.

- (1989b), Delirio y destino (Los viente años de una española). Madrid: Mondadori.

- (1990), Los Bienaventurados. Madrid: Ediciones Siruela.

- (1993), La razón en la sombra. Antología del Pensamiento de María Zambrano. Edición a cargo de Jesús Moreno Sanz. Madrid: Ediciones Siruela.

- (1995), Las palabras del regreso. Edición y presentación de Mercedes Gómez Blesa. Salamanca: Amarú Ediciones. 